\title{
CORRIGENDUM
}

\section{Association of P53 and MSH2 with recombinative repair complexes during S-phase}

Daniele Zink ${ }^{1}$, Christoph Mayr ${ }^{1}$, Christine $\mathrm{Janz}^{2,3}$, and Lisa Wiesmüller ${ }^{2,3}$

Oncogene (2003) 22, 2856. doi:10.1038/sj.onc.1206590

The authors addresses have changed in the following way:

${ }^{1}$ Institut für Anthropologie und Humangenetik LMU München, Goethestr. 31, 80336, München, Germany
${ }^{2}$ Universitätsfrauenklinik and Poliklinik, Prittwitzstrasse 43, D-89075 Ulm, Germany

${ }^{3}$ Heinrich-Pette-Institut für Experimentelle Virologie und Immunologie an der Universität Hamburg, 20251 Hamburg, Germany

\section{P53 and recombination intermediates: role of tetramerization at DNA junctions in complex formation and exonucleolytic degradation}

Christine Janz ${ }^{1,2}$, Silke Süsse ${ }^{1,2}$ and Lisa Wiesmüller ${ }^{1,2}$

Oncogene (2003) 22, 2856. doi:10.1038/sj.onc.1206591

The authors addresses have changed in the following way:
${ }^{1}$ Universitätsfrauenklinik und Poliklinik, Prittwitzstrasse 43, D-89075 Ulm, Germany; ${ }^{2}$ Heinrich-Pette-Institut für Experimentelle Virologie und Immunologie an der Universität Hamburg, D-20251 Hamburg, Germany 